\title{
Retrieving Mean Temperature of Atmospheric Liquid Water Layers Using Microwave Radiometer Measurements
}

\author{
SERGEY Y. MATROSOV \\ Cooperative Institute for Research in Environmental Sciences, University of Colorado Boulder, and NOAA/Earth \\ System Research Laboratory/Physical Sciences Division, Boulder, Colorado \\ DAVID D. TURNER \\ NOAA/Earth System Research Laboratory/Global Systems Division, Boulder, Colorado
}

(Manuscript received 11 October 2017, in final form 22 February 2018)

\begin{abstract}
A remote sensing method to retrieve the mean temperature of cloud liquid using ground-based microwave radiometer measurements is evaluated and tested by comparisons with direct cloud temperature information inferred from ceilometer cloud-base measurements and temperature profiles from radiosonde soundings. The method is based on the dependence of the ratio of cloud optical thicknesses at W-band ( $\sim 90 \mathrm{GHz})$ and Ka-band $(\sim 30 \mathrm{GHz})$ frequencies on cloud liquid temperature. This ratio is obtained from total optical thicknesses inferred from radiometer measurements of brightness temperatures after accounting for the contributions from oxygen and water vapor. This accounting is done based on the radiometer-based retrievals of integrated water vapor amount and temperature and pressure measurements at the surface. The W-Ka-band ratio method is applied to the measurements from a three-channel $(90,31.4$, and $23.8 \mathrm{GHz})$ microwave radiometer at the U.S. Department of Energy Atmospheric Radiation Measurement Mobile Facility at Oliktok Point, Alaska. The analyzed events span conditions from warm stratus clouds with temperatures above freezing to mixed-phase clouds with supercooled liquid water layers. Intercomparisons of radiometer-based cloud liquid temperature retrievals with estimates from collocated ceilometer and radiosonde measurements indicated on average a standard deviation of about $3.5^{\circ} \mathrm{C}$ between the two retrieval types in a wide range of cloud temperatures, from warm liquid clouds to mixed-phase clouds with supercooled liquid and liquid water paths greater than $50 \mathrm{~g} \mathrm{~m}^{-2}$. The three-channel microwave radiometer-based method has a broad applicability, since it requires neither the use of active sensors to locate the boundaries of liquid cloud layers nor information on the vertical profile of temperature.
\end{abstract}

\section{Introduction}

Ground-based microwave radiometer measurements have long been used for retrievals of the total amount of the cloud liquid water in an atmospheric vertical columnliquid water path (LWP) - and total columnar integrated water vapor (IWV) (e.g., Hogg et al. 1983). Dual-channel radiometers with operational frequencies near the water vapor absorption line around $22 \mathrm{GHz}$ and in the transparent atmospheric "window" around $30-35 \mathrm{GHz}$ (Ka band) are traditionally utilized for these measurements (e.g., Turner et al.2007). A third microwave frequency channel centered at around $90 \mathrm{GHz}$ (W band) is often added to increase

\footnotetext{
Corresponding author: Sergey Y. Matrosov, sergey.matrosov@ noaa.gov
}

measurement sensitivity to low values of LWP and IWV (e.g., Westwater et al. 1990; Crewell and Löhnert 2003).

In their traditional applications microwave radiometer measurements do not provide information on the altitudes of the liquid water layers and/or the temperature of these layers. Combinations of different remote sensors and/or model and radiosonde sounding outputs are typically required to obtain this information (e.g., Politovich et al. 1995). Knowledge of the location and temperature of cloud liquid [especially supercooled liquid water (SLW)], however, is important for many practical applications. These applications include remote sensing of aircraft icing conditions, weather modification, characterizing cloud radiative impact, and cloud-precipitation evolution processes.

While the use of vertically pointing radar measurements collocated with radiometer estimates of LWP provides a 
practical tool for retrieving vertical profiles of cloud liquid water content (e.g., Frisch et al. 1998; Löhnert et al. 2001; Ebell et al. 2010), such retrievals are limited to liquid water clouds where radar reflectivity is determined by cloud drops only, which essentially excludes meaningful applications in mixed-phased clouds. Collocated lidar/ceilometer measurements provide estimates of cloud-base height and, with an assumption of cloud layer thicknesses, can be used for relatively robust estimates of the liquid layer temperatures and heights if thermodynamic temperature profiles are known from radiosonde soundings or/and models. These cloud-base measurements, however, are often contaminated and thus unreliable during solid precipitation conditions. Besides, there are many observational sites that have microwave radiometers that do not have active remote sensors.

A remote sensing approach to estimate an average temperature of liquid water layers in winter clouds was suggested by Koldaev et al. (1998). This approach uses measurements from $\sim 90$ - and $\sim 30-\mathrm{GHz}$ microwave radiometer channels only and does not require any additional measurements from active remote sensors. Under the assumption that the liquid water signal dominates radiometer measurements of brightness temperatures (as compared to contributions from atmospheric gases), these authors suggested that the mean cloud liquid thermodynamic temperature can be deduced from the ratio of optical thicknesses at $\mathrm{W}$ - and Ka-band frequencies. This mean cloud temperature can be then related to the heights of liquid water layers if the atmospheric temperature vertical profile is known.

The objectives of the present study include the further development and enhancement of this approach to estimate mean cloud liquid temperature using passive microwave radiometer measurements, and to verify the retrievals obtained from this approach with the independent cloud temperature/height estimates inferred from ceilometer and radiosonde temperature profile observations. The enhancements include accounting for the oxygen and water vapor contributions to the total optical thicknesses inferred from radiometer measurements when estimating liquid water optical thicknesses and using a recently developed model of the dielectric properties of water that spans a wide range of temperatures. The only information additional to the microwave radiometer measurements is near-surface standard meteorological parameters (e.g., air pressure, temperature), which are typically available in most practical situations.

\section{Theoretical background}

\section{a. Estimation of total optical thicknesses}

In the Rayleigh-Jeans approximation, the frequency $\left(\nu\right.$-dependent brightness temperature, $T_{b}$, of downwelling thermal radiation observed in the zenith direction in the absence of liquid precipitation can be expressed as (e.g., Westwater et al. 1990)

$$
T_{b}=T_{c} e^{-\tau}+T_{\mathrm{mr}}\left(1-e^{-\tau}\right),
$$

where $\tau$ is the total absorption optical thickness of the atmosphere, $T_{\mathrm{mr}}$ is the mean radiating temperature in absolute units $(\mathrm{K})$, and $T_{c} \approx 2.8 \mathrm{~K}$ is the brightness temperature of the cosmic background radiation. The optical thickness value can be obtained from (1) as

$$
\tau=\ln \left[\left(T_{\mathrm{mr}}-T_{c}\right) /\left(T_{\mathrm{mr}}-T_{b}\right)\right] .
$$

Information on thermodynamic vertical profiles (e.g., from the radiosonde measurements) can be used for calculating mean radiating temperatures. In the absence of thermodynamic profile measurements, $T_{\mathrm{mr}}$ can be approximately estimated from surface meteorological observations (e.g., Westwater et al. 1990). Based on radiative transfer modeling using a larger dataset of radiosonde vertical profile information, Turner et al. (2007) suggested an approximation for $T_{\mathrm{mr}}(31.4 \mathrm{GHz}) \approx$ $14.3+0.815 T_{\mathrm{sfc}}+0.15 \mathrm{RH}+0.0148 P_{\mathrm{sfc}}$, where $T_{\mathrm{sfc}}$, $\mathrm{RH}$, and $P_{\text {sfc }}$ are the ambient temperature $(\mathrm{K})$, relative humidity $(\%)$, and barometric pressure $(\mathrm{hPa})$ at the surface, respectively. The $31.4-\mathrm{GHz}$ frequency is used in many dual- and triple-frequency microwave radiometers, including ones deployed at some of the U.S. Department of Energy's Atmospheric Radiation Measurement (ARM) Program sites (Turner and Ellingson 2016). This approximation was used in this study for the initial guess of $T_{\mathrm{mr}}$ at this frequency. Model calculations using the Monochromatic Radiative Transfer Model (MonoRTM; Clough et al. 2005) and representative profiles of atmospheric variables from McClatchey et al. (1972) indicate that $T_{\mathrm{mr}}(90 \mathrm{GHz})$ is on average about $3 \mathrm{~K}$ greater than $T_{\mathrm{mr}}(31.4 \mathrm{GHz})$. This average difference was accounted for in the subsequent retrievals.

\section{b. Gaseous optical thicknesses}

The atmospheric optical thickness is the sum of the optical thicknesses resulting from water vapor, $\tau_{\mathrm{wv}}$, cloud liquid water, $\tau_{L}$, and the "dry" (primarily caused by oxygen) components, $\tau_{02}$. The liquid water component, which is of main interest when estimating cloud liquid temperature, is then estimated by subtracting the two gaseous components from the total optical thickness derived from (2):

$$
\tau_{L}=\tau-\tau_{\mathrm{wV}}-\tau_{02}
$$

The ice cloud component to the total optical thickness (if ice hydrometeors are present in the vertical atmospheric column) is typically very small in the $30-90-\mathrm{GHz}$ 
range and is usually neglected in most practical applications (e.g., Hogg et al. 1983).

The oxygen component of the total optical thickness, $\tau_{02}$, can be estimated from near-surface atmospheric pressure and temperature (i.e., $P_{\text {sfc }}$ and $T_{\text {sfc }}$, respectively). This component is approximately proportional to $P_{\mathrm{sfc}}^{2}$ and it diminishes with increasing temperature (e.g., Turner et al. 2007). An approximation in the form $\tau_{02}\left(\nu, P_{\mathrm{sfc}}, T_{\mathrm{sfc}}\right) \approx$ $\tau_{02}\left(\nu, P_{0}, T_{0}\right)\left(P_{\mathrm{sfc}} / P_{0}\right)^{2}\left(T_{\mathrm{sfc}} / T_{0}\right)^{n}$, using the COESA (1976) values of surface pressure and temperature (i.e., $P_{0}=1013 \mathrm{hPa}, T_{0}=288 \mathrm{~K}$ ), has been suggested (e.g., Stepanenko et al. 1987). Calculations using the radiative transfer model MonoRTM and standard atmosphere temperature and pressure vertical profiles yield $\tau_{02}\left(\nu, P_{0}, T_{0}\right)$ values of approximately 0.028 and 0.047 for $\nu \approx 31.4 \mathrm{GHz}$ and $\nu \approx 90 \mathrm{GHz}$, respectively.

Figure 1 shows the ratios of oxygen optical thickness normalized to the surface pressure as a function of $T_{\text {sfc }} / T_{0}$ calculated for pressure, temperature, and humidity profiles from McClatchey et al. (1972) corresponding to tropical, midlatitude summer and winter, and subarctic summer and winter atmospheres, and to the U.S. Standard Atmosphere (COESA 1976). The power-law approximations of the results in Fig. 1 suggest that the exponent $n$ in the $\tau_{02}\left(\nu, P_{\mathrm{sfc}}, T_{\mathrm{sfc}}\right)$ approximation is around -1.20 and -1.75 for the $31.4-$ and $90-\mathrm{GHz}$ frequencies, respectively. These values for the exponent were further used in this study to estimate the oxygen contribution to the total optical thickness from the surface meteorology observations.

The water vapor component of the total optical thickness is proportional to IWV, which is retrieved from microwave radiometer data using the standard approaches for dual- or triple-frequency retrievals of LWP and IWV (e.g., Westwater et al. 1990; Turner et al. 2007; Cadeddu et al. 2013). Model calculations with the standard atmosphere profiles indicate that when normalized to IWV $=1 \mathrm{~mm}$, the values of $\tau_{\mathrm{wv}}\left(\nu, P_{0}, T_{0}\right)$ are about 0.0017 and 0.0083 for $\nu \approx 31.4 \mathrm{GHz}$ and $\nu \approx 90 \mathrm{GHz}$, respectively. The pressure dependence of $\tau_{\mathrm{wv}}$ is approximately linear. Modeling with the McClatchey et al. (1972) profiles of atmospheric parameters indicate a rather weak dependence of $\tau_{\mathrm{wv}}$ on temperature (not shown). For the purpose of this study, the water vapor optical thickness contribution was further approximated as $\tau_{\mathrm{wv}}\left(\nu, P_{\mathrm{sfc}}, T_{\mathrm{sfc}}\right) \approx \operatorname{IWV} \tau_{\mathrm{wv}}\left(\nu, P_{0}, T_{0}\right)\left(P_{\mathrm{sfc}} / P_{0}\right)$, where $\tau_{\mathrm{wv}}\left(\nu, P_{0}, T_{0}\right)$ is normalized to the $1-\mathrm{mm}$ IWV value.

\section{c. Relations between the $\tau_{L}(W) / \tau_{L}(K a)$ ratio and cloud liquid mean temperature}

The ratio of the liquid water components of the total optical thicknesses at W-and Ka-band radiometer frequencies

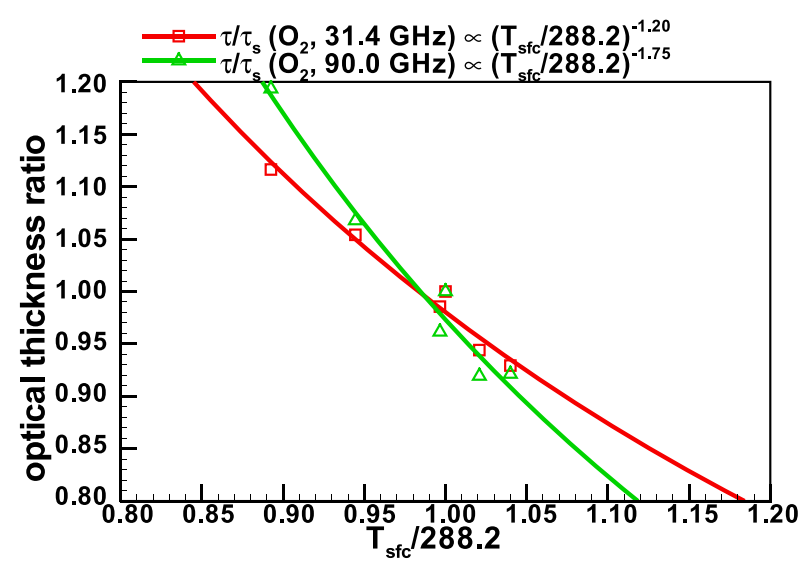

FIG. 1. The ratio of the oxygen optical thicknesses, normalized to $1013 \mathrm{hPa}$, as a function of $T_{\mathrm{sfc}} / 288.2$ for characteristic atmospheric profiles from McClatchey et al. (1972) and COESA (1976).

is used to infer estimates of the mean temperature of cloud liquid. In the Rayleigh scattering regime, which is valid for liquid cloud droplets at microwave frequencies considered here, the liquid cloud absorption coefficient, $\alpha(\nu)$, is proportional to cloud liquid water content (LWC) as (e.g., Matrosov 2009)

$$
\begin{aligned}
\alpha(\nu) & =6 \pi \nu\left(\rho_{w} c\right)^{-1} \operatorname{Im}[-(\varepsilon-1) /(\varepsilon+2)] \mathrm{LWC} \\
& =a(\nu) \mathrm{LWC},
\end{aligned}
$$

where $c, \rho_{w}$, and $\varepsilon$ are the speed of light, density, and complex dielectric permittivity of liquid water, respectively. The $\tau_{L}$ values can be expressed then in terms of the mean cloud liquid water content $\left(\mathrm{LWC}_{m}\right)$ and the total geometrical thickness of liquid cloud layers, $h_{c}$ :

$$
\tau_{L}(\nu)=a(\nu) \mathrm{LWC}_{m} h_{c} .
$$

The permittivity $\varepsilon$ is a strong function of the temperature of the liquid water, so for a given $\mathrm{W}-\mathrm{Ka}$-band frequency pair, the ratio $\tau_{L}(\mathrm{~W}) / \tau_{L}(\mathrm{Ka})$ is a function of mean cloud temperature as the dependence on $\mathrm{LWC}_{m}$, $h_{c}$, and the constants in (4) vanishes when the ratio is taken.

An improved liquid water absorption model was recently developed by Turner et al. (2016). This model uses the Debye (1929) formulation and empirical coefficients derived from a dataset that included both laboratory and field observations of the permittivity of liquid water. The use of this model provides a way of calculating frequency dependent $\varepsilon$ values for a wide range of temperatures, including those in the supercooled range down to the coldest temperatures at which the existence of cloud liquid water is possible.

Figure 2 shows the relations between liquid water temperature and the $\tau_{L}(\mathrm{~W}) / \tau_{L}(\mathrm{Ka})$ ratio as calculated 


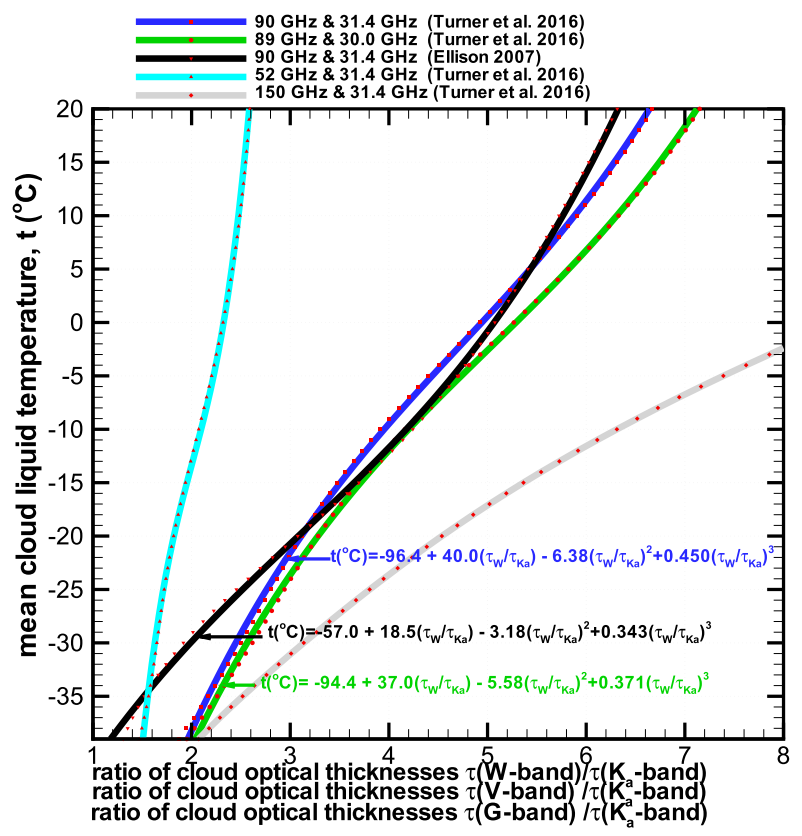

FIG. 2. Correspondence between the ratio of cloud liquid optical thicknesses and mean cloud temperature. Red symbols indicate calculation results, and the curves show the polynomial approximations.

using the Turner et al. (2016) and Ellison (2007) dielectric constant models (symbols) and corresponding polynomial best-fit approximations. As an illustration of the sensitivity to the frequency pair choice, a Turner et al. (2016)-based relation is shown for two W-Ka frequency pairs-(i) 90 and 31.4 and (ii) 89 and $30 \mathrm{GHz}$ - and a $52-\mathrm{GHz}$ (V band) $-31.4-\mathrm{GHz}$ combination. These frequencies are utilized in different commercially available microwave radiometer instruments.

As seen from Fig. 2, the ratio $\tau_{L}(\mathrm{~W}) / \tau_{L}(\mathrm{Ka})$ is very sensitive to temperature [unlike the $\tau_{L}(\mathrm{~V}) / \tau_{L}(\mathrm{Ka})$ ratio]. Hereinafter the lower case $t$ is used for cloud liquid temperatures $\left({ }^{\circ} \mathrm{C}\right)$ as opposed to atmospheric air temperatures $T(\mathrm{~K})$. For a range of liquid cloud temperatures, $t$, between $-40^{\circ}$ and $20^{\circ} \mathrm{C}$, which approximately corresponds to the full dynamic range of $t$ that could be observed, the ratio $\tau_{L}(\mathrm{~W}) / \tau_{L}(\mathrm{Ka})$ changes rather substantially, increasing from about 2 to approximately 7 . The high sensitivity of this ratio to $t$ is promising for remote sensing retrievals of this temperature using operational microwave radiometer measurements. The results of Fig. 2 also suggest that cloud liquid temperature estimates should be tuned to particular microwave radiometer frequencies, as there is variability in the $t$ versus $\tau_{L}(\mathrm{~W}) / \tau_{L}(\mathrm{Ka})$ relations depending on the frequency pair choice.

\section{Examples of the retrievals of cloud liquid temperature}

a. $\tau_{L}(90 \mathrm{GHz}) / \tau_{L}(31.4 \mathrm{GHz})$ ratio-based retrievals

Four representative events observed by a triplefrequency $(90,31.4$, and $23.8 \mathrm{GHz})$ microwave radiometer deployed at the third ARM Mobile Facility (AMF3) at Oliktok Point, Alaska $\left(70.495^{\circ} \mathrm{N}, 149.886^{\circ} \mathrm{W}\right)$, were chosen to illustrate the mean cloud liquid temperature retrievals. Figure 3 shows time series of the LWP and IWV during these events as inferred from the microwave radiometer measurements. LWP and IWV estimates were obtained using a bias-adjusted iterative physical retrieval approach (Cadeddu et al. 2013). The temporal resolution is $\sim 3 \mathrm{~s}$. LWP values greater than about $300 \mathrm{~g} \mathrm{~m}^{-2}$ are often associated with liquid precipitation. Periods with unreliable retrievals, such as those during precipitation conditions, are flagged in the standard microwave radiometer data files available from the ARM archive. Some examples of such periods are shown by arrows in Fig. 3. These periods, which had a "rain" flag in the standard ARM data files, were further excluded from the analysis when estimating mean cloud liquid temperature.

Figure 4 shows the retrievals of total optical thicknesses at 90 and $31.4 \mathrm{GHz}$ using (2) and estimates of optical thickness resulting from liquid water from (3) for the events shown in Fig. 3. Since the liquid cloud absorption coefficient is linearly related to LWC, the temperature retrievals effectively represent the LWC-weighted temperatures of the cloud layer(s). The $\tau_{L}$ values are small for lower LWP, and they are likely to have higher uncertainties because they are estimated as the difference between two larger quantities (i.e., the total optical thickness and the gaseous optical thickness), which also have their own uncertainties. As LWP increases, $\tau_{L}$ begins to dominate the total optical thickness and relative errors of $\tau_{L}$ estimates are expected to decrease. The $\tau_{L}(\mathrm{~W}) / \tau_{L}(\mathrm{Ka})$ ratio-based cloud liquid temperature retrievals are further tested at different thresholds of minimal LWP values $\left(\mathrm{LWP}_{\min }\right)$.

The $\tau_{L}(\mathrm{~W}) / \tau_{L}(\mathrm{Ka})$ ratio-based retrievals of mean cloud liquid temperature for the four dates considered in this study are shown in Fig. 5, where precipitation periods were identified and removed. The $\mathrm{LWP}_{\min }=$ $100 \mathrm{~g} \mathrm{~m}^{-2}$ threshold was applied for these retrievals (i.e., cloud temperature estimates with $\mathrm{LWP}<\mathrm{LWP}_{\min }$ were not considered). Judging from these microwave radiometer-based retrievals, the 15 August 2016 event was mostly characterized by cloud liquid above the freezing level, the temperatures of cloud liquid observed 
a) 15 August 2016, OLI

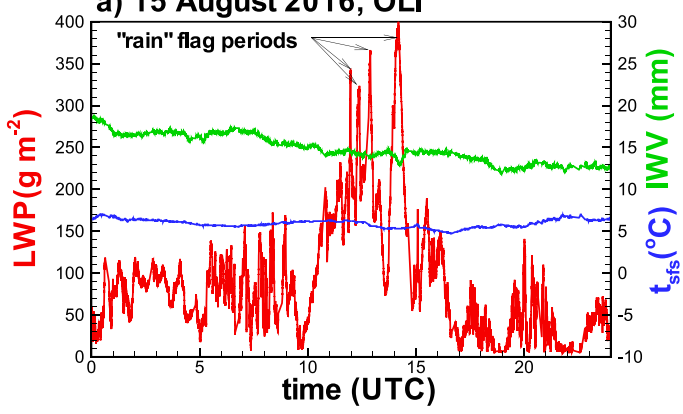

c) 15 October 2016 , OLI

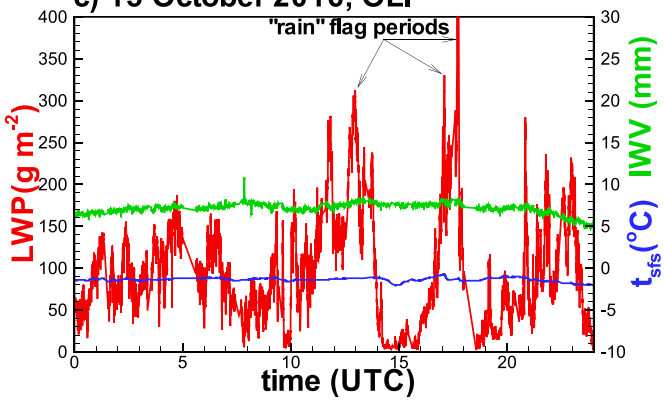

b) 29 August 2016, OLI

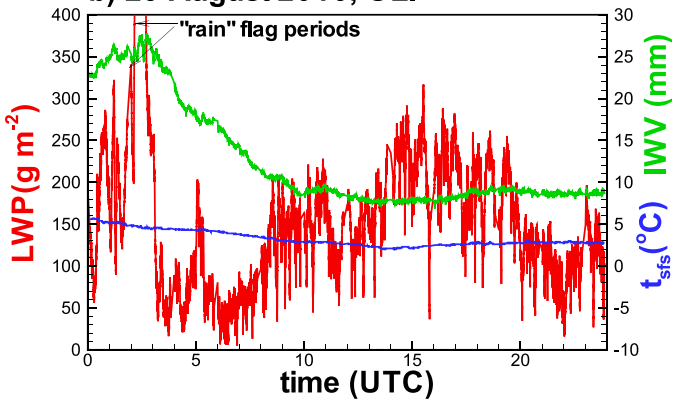

d) 21 October 2016, OLI

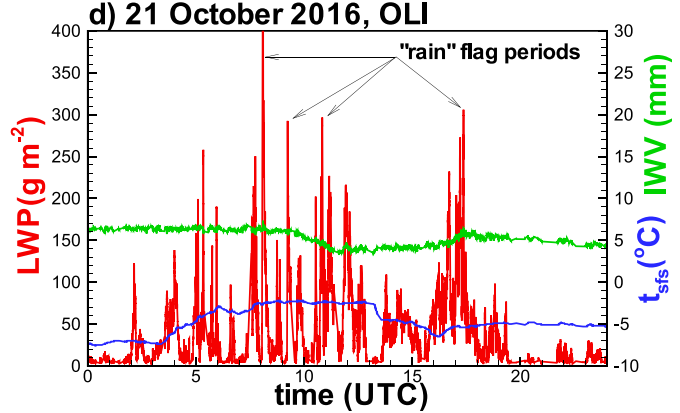

FIG. 3. ARM microwave radiometer retrievals of LWP (red) and IWV (green) at the AMF3 site during (a) 15 Aug, (b) 29 Aug, (c) 15 Oct, and (d) 21 Oct 2016. Near-surface air temperatures are marked (blue lines). Some examples of rain flag periods are shown.

during the 29 August 2016 event were generally around the freezing level, and the two October 2016 cases contained exclusively supercooled liquid. The general temporal trends in mean cloud liquid temperature for

a) 15 August 2016
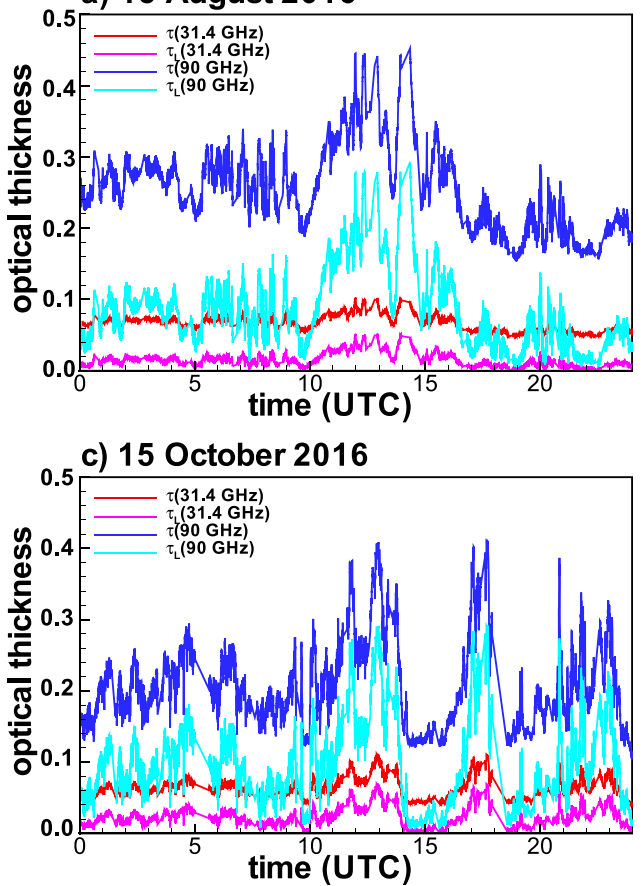

the August and 15 October events were rather small. A much larger change in the retrieved $t$ was observed during the 21 October event between about 0500 and 1300 UTC.
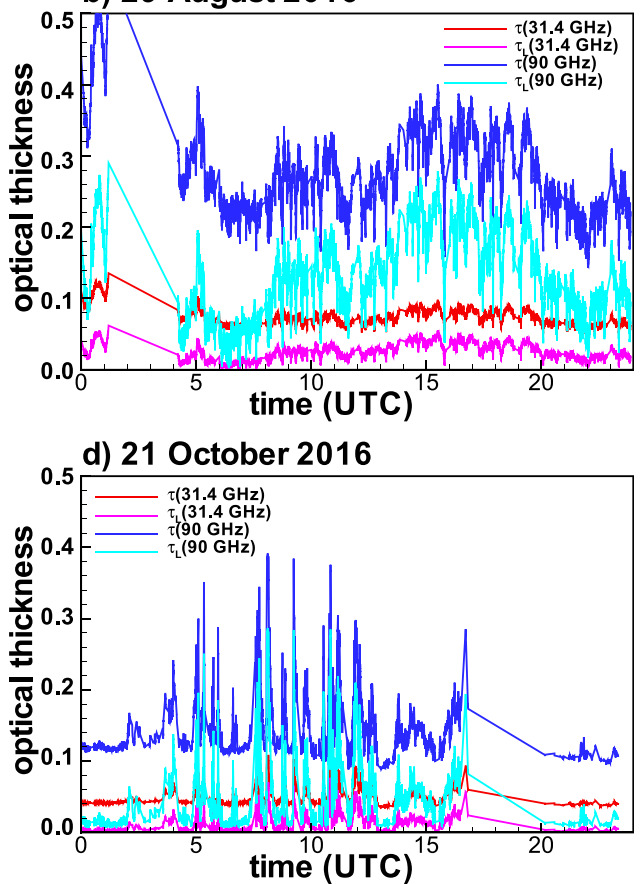

FIG. 4. Total optical thickness and liquid water optical thickness at both 90 and $31.4 \mathrm{GHz}$ for the events shown in Fig. 3. 

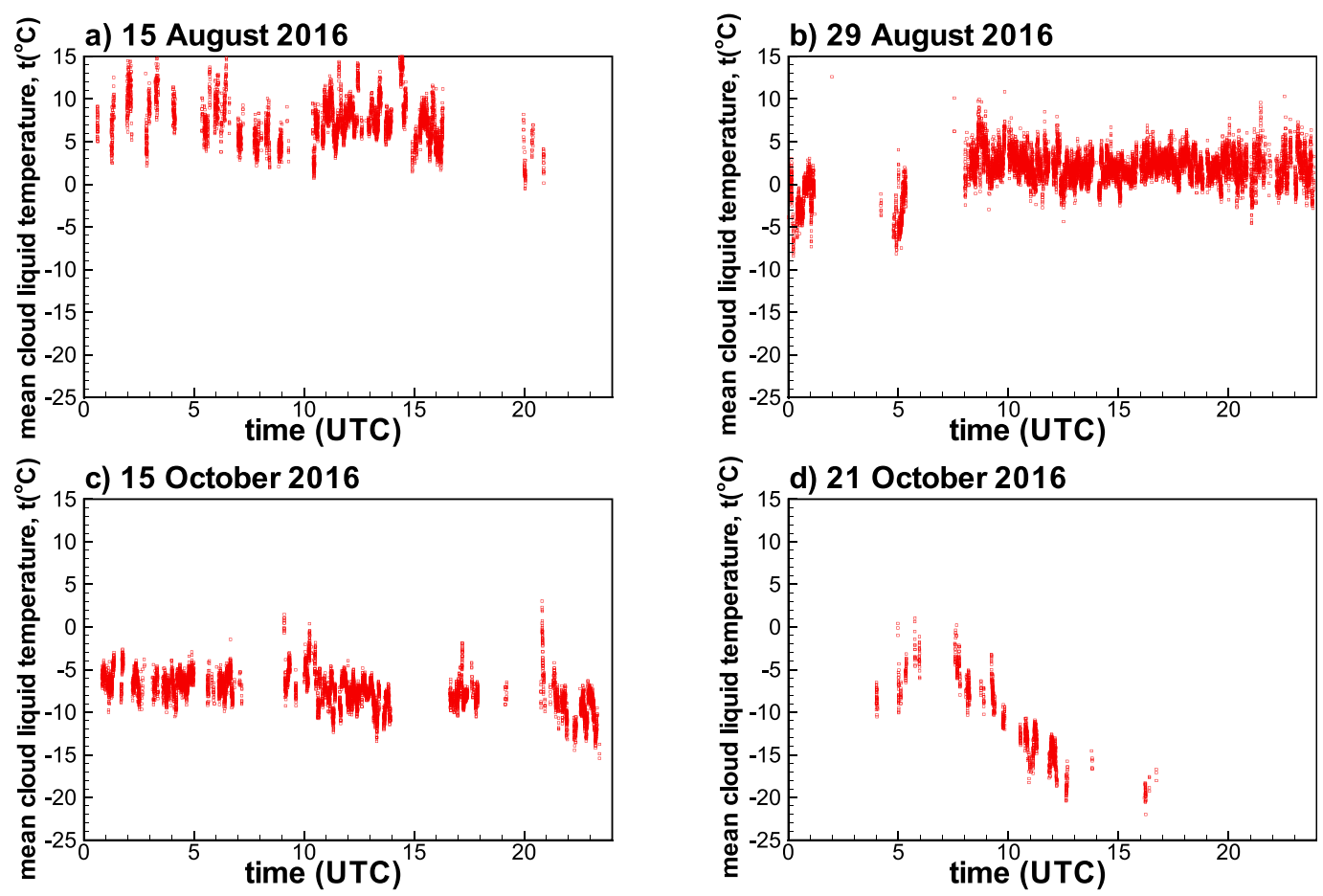

FIG. 5. The $\tau_{L}(\mathrm{~W}) / \tau_{L}(\mathrm{Ka})$ ratio-based retrievals of mean cloud liquid temperature for rain-free periods with LWP > $100 \mathrm{~g} \mathrm{~m}^{-2}$ during (a) $15 \mathrm{Aug}$, (b) $29 \mathrm{Aug}$, (c) 15 Oct, and (d) 21 Oct 2016.

To assess the sensitivity of the $t$ estimates to the approximation of $T_{\mathrm{mr}}$, the retrievals were performed iteratively. After the initial retrieval, the $T_{\mathrm{mr}}$ values were refined assuming that $T_{\mathrm{mr}}(\mathrm{K}) \approx t\left({ }^{\circ} \mathrm{C}\right)+273.16 \mathrm{~K}$ (i.e., assuming that the mean radiative temperature of the atmosphere is close to the mean cloud liquid temperature) for both frequencies and retrievals were performed again. This refinement, however, did not result in substantial variability of the retrieval results, as the standard deviations of the differences between iteratively retrieved $t$ values and those estimated without iterations were about $1.3^{\circ} \mathrm{C}$.

\section{b. Uncertainties of radiometric retrievals}

The uncertainty of the microwave radiometer-based retrieval of the mean cloud liquid temperature, $t$, is generally determined by the accuracy of estimating the $\tau_{L}(\mathrm{~W}) / \tau_{L}(\mathrm{Ka})$ ratio and the uncertainty of the $t-\tau_{L}(\mathrm{~W}) /$ $\tau_{L}(\mathrm{Ka})$ relation. Several factors influence the uncertainty of $\tau_{L}(\mathrm{~W}) / \tau_{L}(\mathrm{Ka})$ ratio estimates. Those factors include uncertainties in the accounting for the oxygen and IWV components of the total optical thickness and uncertainties in the $T_{\mathrm{mr}}$ of the atmosphere. It is also expected that the $\tau_{L}(\mathrm{~W}) / \tau_{L}(\mathrm{Ka})$ ratio uncertainties increase as LWP becomes smaller because cloud contributions to the total optical thickness diminishes compared to contributions from atmospheric gases.
Kneifel et al. (2014) showed that the variability of the $\tau_{L}(\mathrm{~W}) / \tau_{L}(\mathrm{Ka})$ ratio for a given cloud temperature is about \pm 0.4 (their Fig. 4). This variability, if it is assumed that it is representative of $\tau_{L}(\mathrm{~W}) / \tau_{L}(\mathrm{Ka})$ errors, corresponds to errors of approximately $\pm 4^{\circ} \mathrm{C}$ in deriving cloud liquid temperature when the Turner et al. (2016) dielectric constant model is used. As can be seen from Fig. 2, the choice of the dielectric constant model (e.g., Turner et al. 2016 vs Ellison 2007) for a given $\tau_{L}(\mathrm{~W}) / \tau_{L}(\mathrm{Ka})$ value can result in about $\pm 3^{\circ} \mathrm{C}$ uncertainty in retrieved cloud temperature (for $t>-30^{\circ} \mathrm{C}$ ). A combined error retrieval uncertainty then can be expected to be around $\pm 5^{\circ} \mathrm{C}$ if the independence of different error sources is assumed. The temperature retrievals in Fig. 5 show a spread of about $4^{\circ}-5^{\circ} \mathrm{C}$ in the retrieved $t$ values over short time intervals that is consistent with the uncertainty estimates given above.

Another way of estimating the uncertainties of the new retrieval method is by intercomparing the retrieved results and those obtained by traditional existing approaches. For the dataset considered in this study, cloud liquid temperature estimates were also available from multisensor measurements. The next section shows the intercomparison results for several events observed at Oliktok.

\section{c. Multisensor-based retrievals}

The twice-daily radiosonde soundings at the AMF3 site were interpolated in time, thus providing time series 

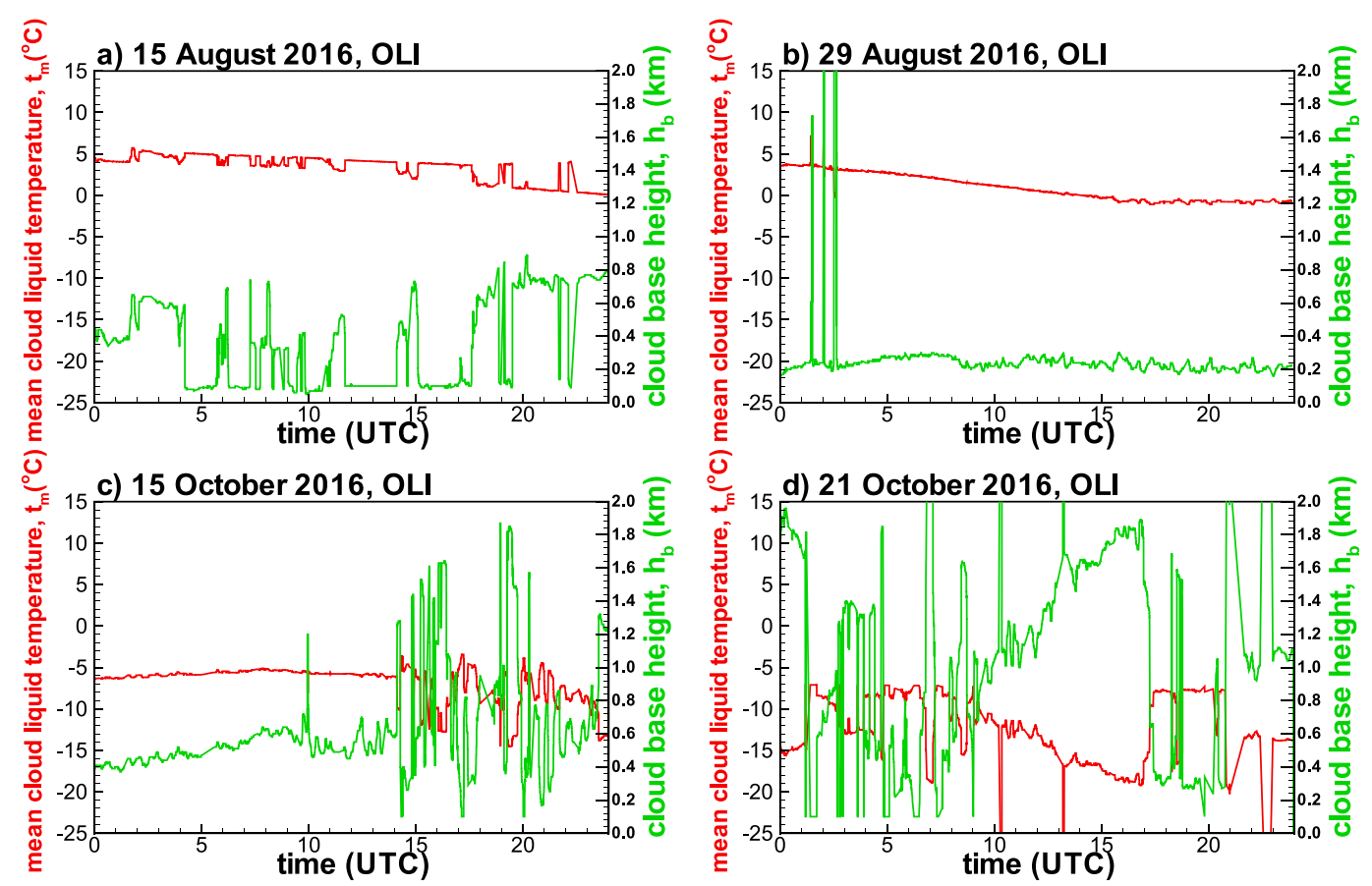

FIG. 6. Multisensor estimates of the mean cloud liquid temperatures (red) and ceilometer-detected cloud-base heights (green) during (a) $15 \mathrm{Aug}$, (b) $29 \mathrm{Aug}$, (c) 15 Oct, and (d) 21 Oct 2016.

of vertical profiles of ambient temperature. A collocated Vaisala laser ceilometer provided estimates of liquid cloud-base heights. Laser radiation propagating in liquid water clouds is usually attenuated rather quickly, so no reliable information on cloud-top heights is available from ceilometer measurements. There is a collocated millimeter-wave cloud radar at the AMF3 site. However, radar signals are typically dominated by the ice hydrometeors and cannot reliably provide cloud tops during mixed-phase conditions. To estimate the cloud temperature from ceilometer and interpolated radiosonde soundings, the geometrical thickness of the liquid water layer, the presence of which is established by the microwave radiometer measurements, was assumed to be $0.3 \mathrm{~km}$. Turner et al. (2018) suggested that the median geometric cloud thickness for single-layer clouds is a function of LWP and cloud phase (i.e., liquid only vs mixed phase), and that the $0.3-\mathrm{km}$ value is a reasonable approximation to cloud geometrical thickness. The mean temperature of this layer was then assumed to be the mean cloud liquid temperature. The corresponding temperature estimates are denoted as $t_{m}$, where the subscript $m$ stands for multisensor (i.e., inferred from multiple instrument measurements, including ceilometer data and interpolated radiosonde temperature profiles).

Figure 6 shows ceilometer cloud-base heights, $h_{b}$, and corresponding estimates of $t_{m}$. It can be seen that $h_{b}$ values are rather discontinuous, except for 29 August 2016 (outside the rain period) and the first half of 15 October 2016. Note a similarity in the temporal trends of $t_{m}$ (Fig. 6) and $t$ (Fig. 5) (e.g., on 21 October 2016). The discontinuities in the $h_{b}$ estimates (possibly caused by multiple cloud layers and breaks in the lower cloud layer) cause a severaldegree variability in $t_{m}$ values on short time scales. In spite of the limitations, multisensor estimates of the cloud liquid temperature described are more direct than radiometerbased retrievals (although not exactly the "truth"), so the $t$ retrievals from the novel microwave radiometer-based method can be compared to $t_{m}$ estimates to assess the potential of this method.

\section{Intercomparisons of $t$ and $t_{m}$}

For LWP $>100 \mathrm{~g} \mathrm{~m}^{-2}$, Fig. 7 shows scatterplots of concurrent retrievals of mean cloud temperature (i.e., $t$ ) from microwave radiometer data and those (i.e., $t_{m}$ ) from multisensor measurements. Overall, the agreement is reasonable given the independence of the two approaches. The dynamic range of the $t_{m}$ variability is, however, somewhat smaller than that for the retrieved $t$ values. This might be partly due to the fact that in the event of multiple liquid layers, microwave radiometerbased retrievals effectively represent the LWP-weighted temperature of the layers, while the multisensor estimates are primarily indicative of the first layer. 


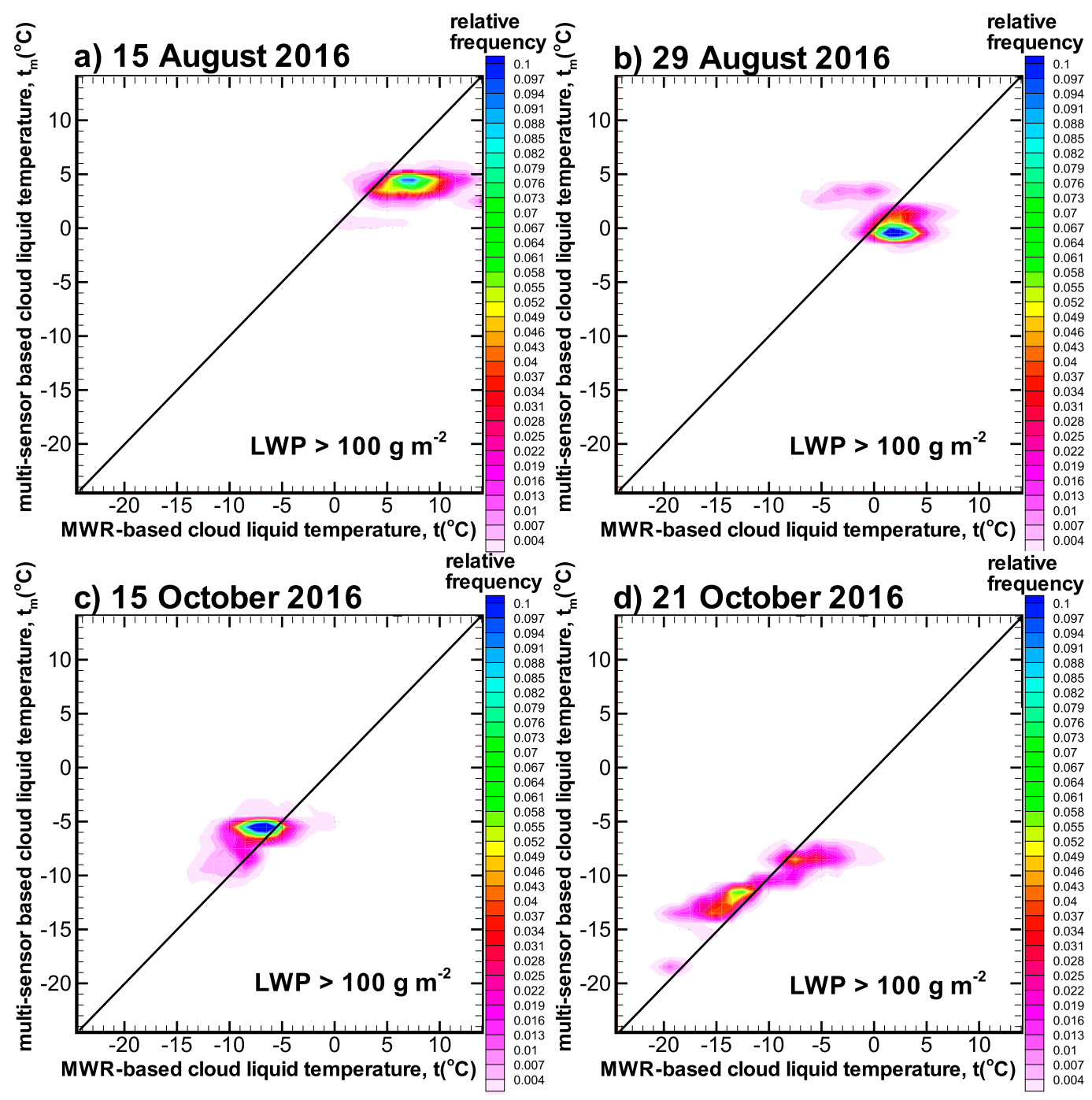

FIG. 7. Two-dimensional frequency histograms of mean cloud liquid temperature inferred from multisensor and microwave radiometer-based measurements for LWP $>100 \mathrm{~g} \mathrm{~m}^{-2}$ during (a) $15 \mathrm{Aug}$, (b) $29 \mathrm{Aug}$, (c) 15 Oct, and (d) 21 Oct 2016.

The cloud liquid temperatures during the 4 days considered here varied over a wide range, from all positive temperatures (15 August 2016) to conditions with a small fraction of supercooled liquid (29 August 2016) to all supercooled liquid with relatively little changing temperatures (15 October 2016) to conditions with substantial changes of supercooled liquid temperature (21 October 2016). For all 4 days, there are overall $\sim 29000$ data points used in Fig. 7 for comparisons. The $t$ dataset is on average biased high by about $1.1^{\circ} \mathrm{C}$ compared to $t_{m}$ estimates, and the standard deviation between $t$ and $t_{m}$ is approximately $3.2^{\circ} \mathrm{C}$. This standard deviation value is consistent with estimates of the uncertainties of the radiometer-based cloud liquid temperature retrievals. Iterative retrievals when the mean radiative temperature for consecutive steps is assumed to be equal to the mean cloud liquid temperature inferred at a previous iteration affect the biases and standard deviation values very modestly. The corresponding changes were generally within $1^{\circ} \mathrm{C}$. The corresponding correlation coefficient between the two estimates of the mean cloud liquid temperature for the entire four-observationalcase dataset is 0.89 .

Changing the minimum threshold value of $L W P_{\min }$, which is used to select the observations from which to retrieve $t$, in the range between 50 and $150 \mathrm{~g} \mathrm{~m}^{-2}$, results in relatively small variability of the correspondence between $t$ and $t_{m}$ (see Table 1). The standard deviations (std dev) are generally larger for larger values of IWV, which indicates higher uncertainties of radiometer-based 
TABLE 1. Mean biases and standard deviations between cloud liquid temperatures estimated from the $\tau_{L}(90 \mathrm{GHz}) / \tau_{L}(31.4 \mathrm{GHz}) \mathrm{ratio}$ and from ceilometer and radiosonde measurements for all four observational cases. The data are for different LWP $\mathrm{P}_{\min }$ thresholds and IWP ranges.

\begin{tabular}{|c|c|c|c|c|c|c|c|c|c|}
\hline \multirow[b]{2}{*}{$\mathrm{LWP}_{\min }\left(\mathrm{g} \mathrm{m}^{-2}\right)$} & \multicolumn{3}{|c|}{ IWV $<10 \mathrm{~mm}$} & \multicolumn{3}{|c|}{$\mathrm{IWV} \geq 10 \mathrm{~mm}$} & \multicolumn{3}{|c|}{ All IWV } \\
\hline & $\operatorname{Bias}\left({ }^{\circ} \mathrm{C}\right)$ & Std dev $\left({ }^{\circ} \mathrm{C}\right)$ & Point No. & $\operatorname{Bias}\left({ }^{\circ} \mathrm{C}\right)$ & Std dev $\left({ }^{\circ} \mathrm{C}\right)$ & Point No. & $\operatorname{Bias}\left({ }^{\circ} \mathrm{C}\right)$ & Std dev $\left({ }^{\circ} \mathrm{C}\right)$ & Point No. \\
\hline 50 & 0.4 & 3.0 & 32115 & 2.0 & 4.8 & 17727 & 1.1 & 3.8 & 49842 \\
\hline 100 & 0.9 & 2.6 & 21244 & 1.8 & 4.6 & 7721 & 1.1 & 3.2 & 28965 \\
\hline 150 & 1.1 & 2.5 & 11175 & 1.8 & 4.5 & 3677 & 1.2 & 3.2 & 14852 \\
\hline
\end{tabular}

retrievals. This is due to the fact that for larger IWV values and the given LWP, the relative cloud contribution to the total optical thickness is smaller.

For smaller values of LWP, retrieving cloud liquid temperature from three-channel microwave radiometer measurements becomes increasingly more challenging because the cloud contribution to the total optical thickness decreases and the estimates of the ratio $\tau_{L}(\mathrm{~W}) / \tau_{L}(\mathrm{Ka})$ generally become less accurate. For LWP $<50 \mathrm{~g} \mathrm{~m}^{-2}$ in the observational dataset considered in this study, the standard deviation between $t$ and $t_{m}$ increases to $11^{\circ} \mathrm{C}$, and for LWP $<15 \mathrm{~g} \mathrm{~m}^{-2}$ the corresponding value is $16^{\circ} \mathrm{C}$.

The multisensor retrievals of mean cloud liquid temperature presented in Fig. 7 assumed that the geometrical thickness of the liquid water cloud layer was $0.3 \mathrm{~km}$. When the ice hydrometeors are not present, the liquid cloud-top heights can be approximately estimated by the maximum altitudes of return echo signals from cloud radars. Among the observations analyzed in this study, such cloud conditions were present during the relatively warm summer observational events on 15 August 2016 (after about 1800 UTC) and, especially, on 29 August 2016 (after about 0500 UTC).

As an illustration, Fig. 8a shows the time-height cross section of the radar reflectivity factor observed on 29 August 2016 by the vertically pointing Ka-band ARM zenith radar (KAZR; Kollias et al. 2016), which was collocated with the microwave radiometer and ceilometer at the Oliktok Point ARM facility. Outside the liquid precipitation period prior to about 0400 UTC, KAZR echo tops were observed mostly between about 0.5 and $0.8 \mathrm{~km}$. Since the ceilometer cloud-base heights during these observations were around $0.2-0.3 \mathrm{~km}$, the $0.3-\mathrm{km}$ assumption for the total geometrical thickness of the liquid cloud layer could be rather reasonable, though actual geometrical thicknesses can vary and exceed $0.3 \mathrm{~km}$ for some periods during this observational event.

Judging from the absence of noticeable decreases of KAZR reflectivity with height (Fig. 8a) as a result of attenuation, liquid precipitation during the beginning of the 29 August event was quite weak (e.g., Matrosov
2005) and was not characterized by large amounts of rainwater path. A reflectivity decrease toward the ground is indicative of rain evaporation. Low reflectivity streaks during stratus observations (after 0600 UTC 19 August 2016 and before 1200 UTC 15 October 2016) below the cloud-base suggest the possible presence of drizzle. The reflectivity bright band on 29 August 2016 ( $\sim 200$ UTC) suggests that the freezing level during precipitation was at an altitude of about $2.2 \mathrm{~km}$. During the course of the event, however, cloud liquid temperatures decreased slightly (Fig. 3b).

Identifying liquid cloud layer tops from radar data is problematic when ice hydrometeors are present in the
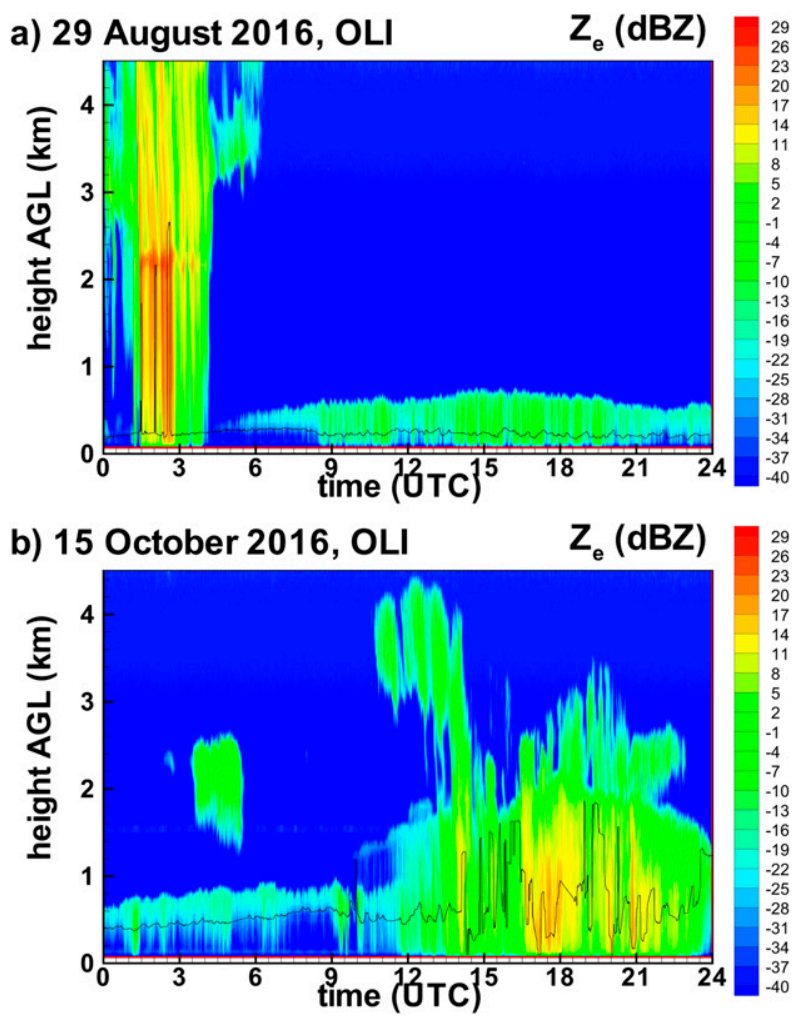

FIG. 8. Oliktok Point KAZR reflectivity measurements on (a) 29 Aug and (b) 15 Oct 2016. Ceilometer cloud-base heights are marked (black lines). 
atmospheric column, as can be seen in Fig. 8b, which shows the KAZR measurements on 15 October 2016. On this date the lower hydrometeor layer with echo tops at around $0.8 \mathrm{~km}$ during the first $9 \mathrm{~h}$ of observations was likely a mostly liquid cloud. Much thicker and stronger radar echoes during the second half of 15 October 2016 are indicative of the presence of ice hydrometeors.

To assess the sensitivity of multisensor estimates of mean cloud liquid temperature to the assumption of the cloud geometrical thickness, these estimates were performed assuming also the liquid water cloud layer to be $0.5 \mathrm{~km}$ instead of $0.3 \mathrm{~km}$. Comparisons of multisensor estimates assuming $0.3-$ and $0.5-\mathrm{km}$ cloud geometrical thickness with the $\tau_{L}(90 \mathrm{GHz}) / \tau_{L}(31.4 \mathrm{GHz})$ ratiobased temperature estimates resulted only in slight changes of the mean bias and standard deviation values (not shown). The corresponding changes were generally within a few tenths of $1^{\circ} \mathrm{C}$.

\section{Discussion and conclusions}

Differing temperature dependencies of the complex refractive indices of water at $\mathrm{W}$ - and Ka-band microwave frequencies provide a unique tool to retrieve mean cloud liquid water temperature in liquid and mixedphase clouds solely from ground-based three-channel microwave radiometer measurements and standard meteorological measurements of temperature and pressure near the surface. Such radiometers are typically used to obtain estimates of liquid water path (LWP) and integrated water vapor (IWV) amount in the vertical atmospheric column. Traditional remote sensing approaches to estimate cloud liquid temperature usually involve results of radiosonde thermodynamic profile sounding and measurements from active remote sensors (e.g., ceilometers). Measurements from active remote sensor measurements, however, are not always available and (even when available) can be compromised by complicated meteorological conditions (e.g., the presence of solid hydrometeor precipitation).

The proposed three-channel microwave radiometerbased approach to retrieve mean cloud liquid temperature is based on estimates of the ratio of liquid cloud optical thickness contributions [i.e., $\tau_{L}(\mathrm{~W}) / \tau_{L}(\mathrm{Ka})$ ], which is a unique function of liquid temperature for a particular frequency pair. This ratio changes monotonically from about 2 to approximately 7 as the temperature increases from $-30^{\circ}$ to $20^{\circ} \mathrm{C}$. The total optical thicknesses are inferred from the radiometric brightness temperature measurements, and the cloud contributions are then obtained from these optical thicknesses by subtracting the atmospheric gases contributions, which are estimated using the standard surface meteorological measurements of pressure and temperature and IWV retrievals.

Although the cloud liquid temperature retrievals do not use LWP, they are inherently more accurate for larger LWP values (i.e., when the total optical thicknesses are dominated by liquid). The use of higher frequencies such as those at $\mathrm{G}$ band (e.g., $\sim 150 \mathrm{GHz}$ ) instead of $\mathrm{W}$ band could be potentially beneficial for improving the accuracy of the cloud liquid water temperature retrievals because for the G-Ka-band frequency pair, the ratio of optical thicknesses varies with temperature in a larger dynamic range compared to the W-Ka-band pair (see Fig. 2). Gaseous absorption by oxygen and water vapor, however, is also stronger at higher frequencies. Radiometers with G-band frequencies are not yet as common as those utilizing W-band frequencies.

The radiometer-based method was tested using warm liquid and supercooled liquid mixed-phase cloud observations performed at the ARM Mobile Facility deployed at Oliktok Point, Alaska. The microwave radiometer used at this facility operated at three frequencies-23.8, 31.4, and $90 \mathrm{GHz}$-so the cloud temperature retrievals used the ratio $\tau_{L}(90 \mathrm{GHz}) /$ $\tau_{L}(31.4 \mathrm{GHz})$. Ceilometer and interpolated radiosonde measurements were available for these cloud observations, so the results of the radiometer-based cloud liquid temperature retrievals could be compared with the more direct multisensor measurements involving active remote sensors. While not being exactly a "ground truth," these more direct measurements provided a convenient way of evaluating the novel microwave radiometerbased approach.

The retrieved cloud liquid temperature may not correspond closely to temperatures of cloud base/top for a geometrically thick cloud layer. When multiple liquid layers are present in the atmospheric column, the radiometer-based retrieval effectively represents the LWP weighted temperature of these layers, which may correspond to the atmospheric temperature between the layers. This is a limitation of the passive radiometric measurements. The multisensor approach, however, also suffers limitations when observing multiple liquid layers, as ceilometer measurements are mostly representative of the lowest liquid layer as a result of the extinction of the laser radiation by the cloud particles. Given the uncertainties of both approaches, the comparison results indicated a generally reasonable agreement between radiometer-based and multisensor retrievals for the entire range of observed temperatures from about $-15^{\circ}$ to approximately $5^{\circ} \mathrm{C}$. The radiometerbased cloud liquid temperatures were on average biased high by around $1.1^{\circ} \mathrm{C}$ with a standard deviation of about 
$3.2^{\circ} \mathrm{C}$ relative to multisensor estimates when only samples with LWP $>100 \mathrm{~g} \mathrm{~m}^{-2}$ were compared. Modestly increasing/decreasing the LWP threshold results in some relatively modest changes in the agreement between the two types of retrievals. Microwave radiometer-based retrievals for LWP $<50 \mathrm{~g} \mathrm{~m}^{-2}$, however, become increasingly less certain as the reliability of estimating the $\tau_{L}(\mathrm{~W}) / \tau_{L}(\mathrm{Ka})$ ratio drops. Future testing under a wider range of environmental conditions could provide more information on the applicability of the radiometerbased method.

The results presented here utilize passive radiance observations from the $\mathrm{Ka}$ and $\mathrm{W}$ bands (i.e., around 30 and $90 \mathrm{GHz}$, respectively). However, the most commonly available microwave radiometers are multichannel Ka- and V-bands (i.e., 22-31 and 52-60 GHz, respectively) systems. A natural question is, How well will this technique work using 31 and $52 \mathrm{GHz}$, where the latter frequency was chosen, as it is the most transparent channel in V-band radiometers? The ratio of the liquid water optical thicknesses for this frequency combination is also shown in Fig. 2. Whereas the optical thickness ratio using $\mathrm{W}$-/Ka-band frequencies spans from approximately 2 to 7 over the temperature range of $-35^{\circ}$ to $+20^{\circ} \mathrm{C}$, a corresponding ratio using $\mathrm{V}-\mathrm{Ka}$-band frequencies spans a much narrower range, from approximately 1.5 to 2.5 . This narrow range would result in much larger uncertainties in the derived liquid water cloud temperature, thereby the V-Ka-band combination has significant limitations for estimating cloud liquid temperatures.

This study shows that the temperature of the liquid water cloud can be determined using passive microwave radiometer observations of the liquid water optical thickness ratio at $\mathrm{W}-\mathrm{Ka}$ frequencies, and while the the use of the method has been demonstrated using Arctic data, it is not limited to high-latitude applications. Furthermore, these microwave radiometer-based retrievals of mean cloud liquid temperature can be potentially used for estimating the altitudes of liquid cloud layers if vertical profiles of ambient air temperature are known (e.g., from weather models or soundings) and cloud boundary information is absent because of either the lack of active remote sensors or the unreliability of this information from such sensors (e.g., because of solid precipitation). Since both the amount and the temperature of the supercooled liquid could be available from the same sensor (i.e., a three-channel microwave radiometer), the practical application of such enhanced radiometer-based retrievals could include the detection of aircraft icing conditions. Liquid layer temperature information can also be useful in interpreting cloud-precipitation microphysical processes, especially in wintertime conditions.
Acknowledgments. This study was sponsored by the U.S. Department of Energy Atmospheric System Research Program under Award DE-SC0013306 (PI: Gijs de Boer). The help of Maximilian Maahn in processing the physical microwave radiometer retrieval files is appreciated.

\section{REFERENCES}

Cadeddu, M., 2013: Microwave Radiometer, 3 Channel (MWR3C). ARM Mobile Facility (OLI) Oliktok Point, Alaska; AMF3 (M1) (updated hourly). Atmospheric Radiation Measurement Climate Research Facility Data Archive, accessed 12 December 2017, https://doi.org/10.5439/1025248.

_ J. C. Liljegren, and D. D. Turner, 2013: The Atmospheric Radiation Measurement (ARM) Program network of microwave radiometers: Instrumentation, data, and retrievals. Atmos. Meas. Tech., 6, 2359-2372, https://doi.org/10.5194/amt6-2359-2013.

Clough, S. A., M. W. Shephard, E. J. Mlawer, J. S. Delamere, M. J. Iacono, K. Cady-Pereira, S. Boukabara, and P. D. Brown, 2005: Atmospheric radiative transfer modeling: A summary of the AER codes. J. Quant. Spectrosc. Radiat. Transfer, 91, 233244, https://doi.org/10.1016/j.jqsrt.2004.05.058.

COESA, 1976: U.S. Standard Atmosphere, 1976. NOAA, 227 pp.

Crewell, S., and U. Löhnert, 2003: Accuracy of cloud liquid water path from ground-based radiometry 2. Sensor accuracy and synergy. Radio Sci., 38, 8042, https://doi.org/10.1029/ 2002RS002634.

Debye, P. J. W., 1929: Polare Molekeln. S. Hirzel Verlag, 200 pp.

Ebell, K., U. Löhnert, S. Crewell, and D. D. Turner, 2010: On characterizing the error in remotely sensed liquid water content profile. Atmos. Res., 98, 57-68, https://doi.org/10.1016/ j.atmosres.2010.06.002.

Ellison, W. J., 2007: Permittivity of pure water, at standard atmospheric pressure, over the frequency range $0-25 \mathrm{THz}$ and the temperature range $0-100^{\circ}$ C. J. Phys. Chem. Ref. Data, 36, 1-18, https://doi.org/10.1063/1.2360986.

Ermold, B., and V. Morris, 2013: Ceilometer (CEIL). ARM Mobile Facility (OLI) Oliktok Point, Alaska; AMF3 (M1) (updated hourly). Atmospheric Radiation Measurement Climate Research Facility Data Archive, accessed 23 October 2016, https://doi.org/10.5439/1181954.

Frisch, A. S., C. W. Fairall, G. Feingold, T. Utall, and J. B. Snider, 1998: On cloud radar and microwave radiometer measurements of stratus cloud liquid water profiles. J. Geophys. Res., 103, 23 195-23 197, https://doi.org/10.1029/98JD01827.

Giangrande, S., and T. Toto, 2013: Interpolated sonde (INTERPOLATEDSONDE). ARM Mobile Facility (OLI) Oliktok Point, Alaska; AMF3 (M1) (updated hourly). Atmospheric Radiation Measurement Climate Research Facility Data Archive, accessed 19 April 2017, https://doi.org/10.5439/1095316.

Hogg, D. C., F. O. Guiraud, J. B. Snider, M. T. Decker, and E. R. Westwater, 1983: A steerable dual-channel microwave radiometer for measurement of water vapor and liquid in the troposphere. J. Climate Appl. Meteor., 22, 789-806, https://oi.org/ 10.1175/1520-0450(1983)022<0789:ASDCMR >2.0.CO;2.

Kneifel, S., S. Redl, E. Orlandi, U. Löhnert, M. Cadeddu, D. Turner, and M.-T. Chen, 2014: Absorption properties of supercooled liquid water between 31 and $225 \mathrm{GHz}$ : Evaluation of absorption models using ground-based observations. 
J. Appl. Meteor. Climatol., 53, 1028-1045, https://doi.org/ 10.1175/JAMC-D-13-0214.1.

Koldaev, A. V., E. N. Kadygrov, A. V. Troitsky, and J. W. Strap, 1998: Remote sensing of average liquid water content layer height in winter clouds. Proceedings of the Eighth Atmospheric Radiation Measurement (ARM) Science Team Meeting, U.S. Department of Energy Rep. DOE/ER-0738, UC-402, 381-385.

Kollias, P., and Coauthors, 2016: Development and applications of ARM millimeter-wavelength cloud radars. The Atmospheric Radiation Measurement (ARM) Program: The First 20 Years, Meteor. Monogr., No. 57, Amer. Meteor. Soc., doi:10.1175/ AMSMONOGRAPHS-D-15-0037.1.

Löhnert, U., S. Crewell, A. Macke, and C. Simmer, 2001: Profiling cloud liquid water by combining active and passive microwave measurements with cloud model statistics. J. Atmos. Oceanic Technol., 18, 1354-1366, https://doi.org/10.1175/1520-0426 (2001)018<1354:PCLWBC>2.0.CO;2.

Matrosov, S. Y., 2005: Attenuation-based estimates of rainfall rates aloft with vertically pointing- $\mathrm{K}_{\mathrm{a}}$-band radars. J. Atmos. Oceanic Technol., 22, 43-54, https://doi.org/10.1175/JTECH-1677.1.

, 2009: A method to estimate vertically integrated amounts of cloud ice and liquid and mean rain rate in stratiform precipitation from radar and auxiliary data. J. Appl. Meteor. Climatol., 48, 1398-1410, https://doi.org/10.1175/ 2009JAMC2106.1.

Matthews, B., B. Isom, D. Nelson, I. Lindenmaier, J. Hardin, K. Johnson and N. Bharadwaj, 2015: Ka ARM zenith radar (KAZRGE). ARM Mobile Facility (OLI) Oliktok Point, Alaska; AMF3 (M1) (updated hourly). Atmospheric Radiation Measurement Climate Research Facility Data Archive, accessed 9 January 2017, https://doi.org/10.5439/1025214.
McClatchey, R.A., R. W. Fenn, J. A. A. Selby, F. E. Volz, and J. S. Garing, 1972: Optical properties of the atmosphere. Air Force Cambridge Research Laboratories Environmental Research Papers 331, AFCRL 70-0527, 85 pp.

Politovich, M. K., B. B. Stankov, and B. E. Martner, 1995: Determination of liquid water altitudes using combined remote sensors. J. Appl. Meteor., 34, 2060-2075, https://doi.org/ 10.1175/1520-0450(1995)034<2060:DOLWAU>2.0.CO;2.

Stepanenko, V. D., G. G. Shchukin, L. P. Bobylev, and S. Y. Matrosov, 1987: Microwave Radiometry in Meteorology. Gidrometeoizdat, 284 pp.

Turner, D. D., and R. G. Ellingson, Eds., 2016: The Atmospheric Radiation Measurement (ARM) Program: The First 20 Years. Meteor. Monogr., No. 57, Amer. Meteor. Soc.

—, A. A. Clough, J. C. Liljegren, E. E. Clothiaux, K. E. Cady-Pereira, and K. L. Gaustad, 2007: Retrieving liquid water path and precipitable water vapor from Atmospheric Radiation Measurement (ARM) microwave radiometers. IEEE Trans. Geosci. Remote Sens., 45, 3680-3690, https://doi.org/10.1109/TGRS.2007.903703.

_- S. Kneifel, and M. P. Cadeddu, 2016: An improved liquid water absorption model at microwave frequencies for supercooled water clouds. J. Atmos. Oceanic Technol., 33, 33-44, https://doi.org/10.1175/JTECH-D-15-0074.1.

_ M. D. Shupe, and A. B. Zwink, 2018: Characteristic atmospheric radiative heating rate profiles in Arctic clouds observed at Barrow, Alaska. J. Appl. Meteor. Climatol., 57, 953968, https://doi.org/10.1175/JAMC-D-17-0252.1.

Westwater, E. R., J. B. Snider, and M. J. Falls, 1990: Ground-based radiometric observations of atmospheric emission and attenuation at 20.6, 31.65, and 90.0 GHz: A comparison of measurements and theory. IEEE Trans. Antennas Propag., 38, 1569-1579, https://doi.org/10.1109/8.59770. 